

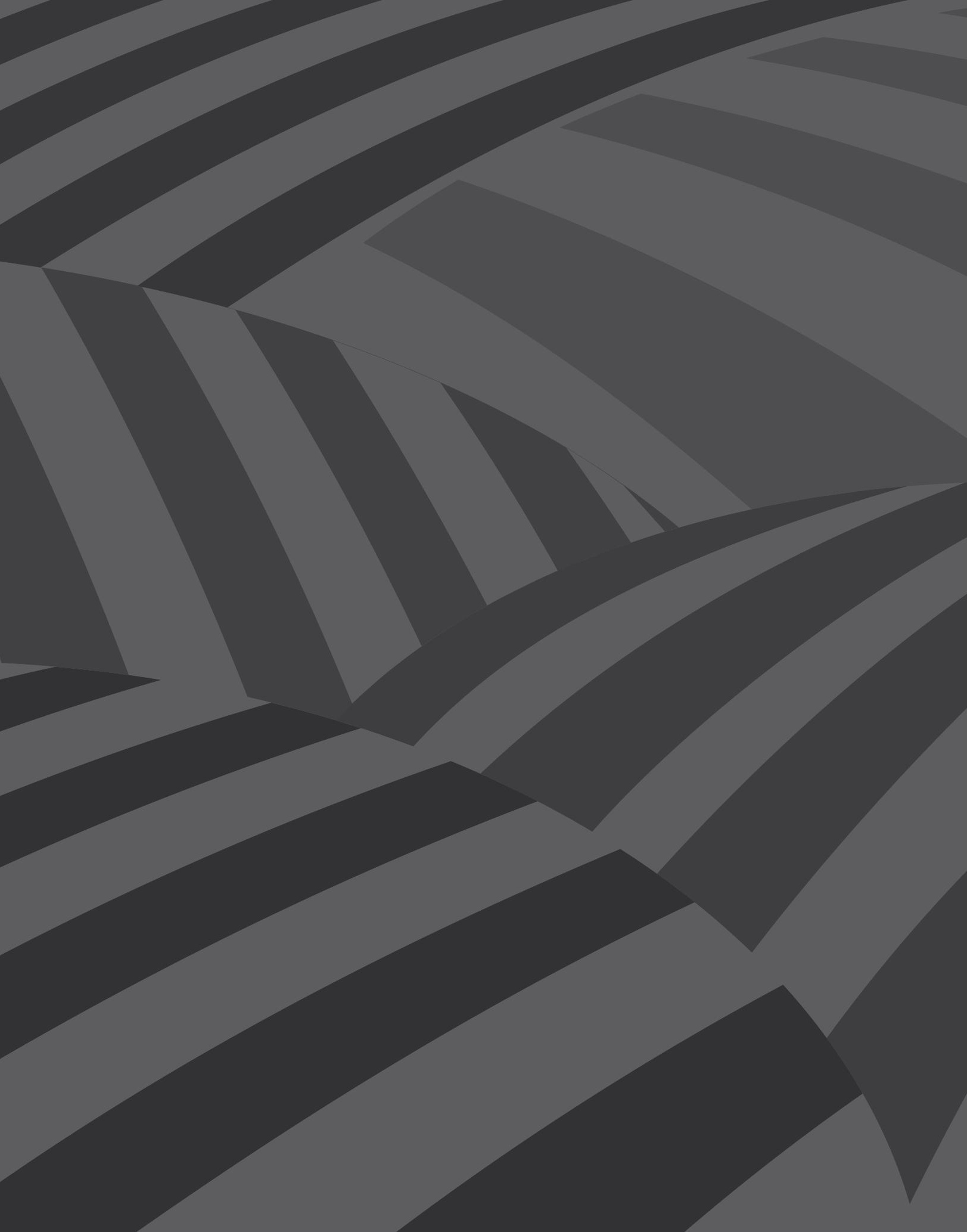




\title{
Agenciamiento de la memoria social en la escuela colombiana como mecanismo reparador
}

\author{
Por Ingrid Lorena Torres Gámez*
}

Resumen: El presente trabajo tiene como principal objetivo reflexionar sobre el papel de la escuela en los ejercicios de reparación de afectaciones acaecidas en el marco del conflicto armado en Colombia. Para dicha tarea, resulta importante reconocer que hace aproximadamente tres décadas las Ciencias Sociales asisten al crecimiento exponencial de trabajos que sitúan la memoria como elemento sustancial en la comprensión del pasado y su incidencia en los discursos sociales, políticos, culturales y normativos del presente, frente a los cuales la escuela no es indiferente, pues se encuentra en un lugar privilegiado para la producción y reproducción de discursos relacionados con los ejercicios de memoria. En este sentido, se acude metodológicamente al orden cualitativo de revisión bibliográfica, enfatizada en la localización y recuperación de información para construir reflexiones desde la óptica de la pedagogía de la memoria, que, más que conclusiones, se conciben como abrebocas ante la mirada multidisciplinar con la que es necesario asumir los retos del reconocimiento de las diversas formas de reparar en la escuela.

Palabras clave: memoria social, conflicto armado, escuela, reparación.

\section{Social memory agency in the Colombian school as a reparation mechanism}

Abstract: The aim of this article is to reflect on the role of the school in the exercises for making amends that have occurred in the context of the armed conflict in Colombia. For this task, it is important to recognize that approximately three decades ago Social Sciences attended the exponential growth of works that place the memory as a substantial element in the understanding of the past and its incidence in the social, political, cultural and normative discourses of the present, in which the school is not indifferent, because it is on a privileged place for the production and reproduction of discourses related to memory exercises. In this sense, a methodological approach is done tothe qualitative order of bibliographic

* Licenciada en Ciencias Sociales, magíster en Historia, docente de la Corporación Universitaria Minuto de Dios. Correo electrónico: ltorresoei@gmail.com. 
review, emphasized in the location and retrieval of information, to build reflections from the perspective of the pedagogy of memory, which, more than conclusions, are conceived as an appetizer before the multidisciplinary view that is necessary to assume the challenges of the recognition of the diverse forms to make amend for the school.

Keywords: social memory, armed conflict, school, to make amend for.

Cómo citar este artículo: Torres Gámez, Ingrid Lorena (2017). Agenciamiento de la memoria social en la escuela colombiana como mecanismo reparador. Revista Controversia, 209, 171-204.

Fecha de recepción: 2 de septiembre del 2017

Fecha de aprobación: 25 de octubre del 2017

\section{A manera de introducción}

$\mathrm{P}$ ara hablar del agenciamiento de la memoria en la escuela, conviene comenzar acotando el contexto en el que se propone esta acción, al igual que las implicaciones de promover procesos de reparación con ejercicios de memoria de un tema específico como es el conflicto armado. Conforme esto, este texto reconoce las preocupaciones, discusiones y reflexiones en torno al desarrollo de este tema; sin embargo, privilegia el aspecto pedagógico para hablar de reparación en el escenario escolar.

En las siguientes páginas se presentan algunos apuntes relacionados con memoria, escuela y reparación en diálogo con postulados que enriquecen las lecturas del contexto colombiano frente al tema, sus avatares, debilidades y retos, pues se trata de un campo de confluencia que, por tratarse de un fenómeno del tiempo presente, refleja un flujo dinámico de producción de publicaciones, eventos, grupos de investigación y contenido en redes sociales, que expresan la convergencia de las relaciones de poder, fragilidades temporales, disputas discursivas y configuraciones espaciales que en la mayoría de ocasiones responden a una sociedad polarizada, con intereses políticos y económicos develados sobre la forma en que se presenta y tramita el pasado. 
En este orden de ideas, el escenario escolar se entiende como objeto de análisis y reflexión, donde es pertinente abordar el pasado reciente en el marco del proceso transicional y las formas en las que esto puede aportar a la reparación de las víctimas directas e indirectas del conflicto armado. Se sobreentiende que es un espacio heterogéneo, al que en el ámbito de la reparación integral le aquejan responsabilidades respecto a la creación y promoción de pedagogías de la memoria en clave de la construcción de paz.

En lo que refiere a la noción de reparación, esta pasa por agenciamientos, producciones y deconstrucciones semióticas que realiza la sociedad civil frente a su historia, su interpretación y reproducción. Los ejercicios de reparación en Colombia, como se mencionará más adelante, responden a un momento histórico especifico del país, donde el Estado ha concebido la reparación como requisito para construir tránsitos hacía la paz y en donde las personas o colectivos que han sido víctimas del conflicto armado, la institucionalidad, las organizaciones sociales y la academia, entre otros, son portadores de pistas para el abordaje social del pasado, la otorgación de sentido al presente y la generación de expectativas de futuro.

En este contexto, la memoria social ha encontrado un lugar clave para el entendimiento y la reconstrucción de pasados irrumpidos, ha sido garante de la elaboración y el afrontamiento de traumas generados por violencias extremas (Rufer, 2009, p.20). Los estudios de la memoria son parte de los cambios paradigmáticos de las Ciencias Sociales de los últimos años del siglo xx como la crisis de los totalitarismos, el protagonismo del giro lingüístico y la psicología social; la memoria social hizo parte del acercamiento metodológico entre las disciplinas sociales, que reafirmó que las interpretaciones del pasado son elementos importantes en la reconstrucción de identidades individuales y colectivas de sociedades que han vivido períodos de violencia (Jelin, 2002).

Los ejercicios de memoria evidenciaron el interés por comprender las facultades psíquicas, emocionales y físicas vinculadas al recuerdo y al 
olvido. Entre otras cosas, el espacio, el tiempo y la narrativa tomaron fuerza como nociones contextuales desde las que el ser humano elabora el pasado. El carácter excepcional de estas tres fue argumentado teniendo en cuenta que la rememoración está asociada al espacio, pues en este se otorga sentido a los lugares del pasado y del presente, los cuales a la vez son recordados, olvidados y resemantizados; además, los recuerdos cuentan con una temporalidad que da carácter cronológico a la estructura de eventos significantes y significados desde la experiencia, materializados en la narrativa de un relato público o privado de quien construye una versión sobre el pasado (Blair, 2005).

Alrededor de estas ideas, en Colombia se ha desarrollado una variedad de aportes metodológicos y conceptuales para el tratamiento de las memorias sociales del conflicto armado; las tres nociones anteriormente mencionadas han sido abordadas a la luz de experiencias transicionales de países como Sudáfrica y Guatemala, destacando la elaboración de relaciones asertivas, la resolución no violenta de los conflictos, la responsabilidad social y la proyección experiencial que involucra el reconocimiento del espacio, el tiempo y la narrativa como parte esencial de las memorias.

Trabajos recientes como el de Grunebaum y Castillejo (2007), sobre la reparación en África y América Latina, califican los ejercicios de memoria y reparación generados en el marco de las comisiones de la verdad como tecnologías de gobernabilidad. Los autores afirman que se trata de esfuerzos nacionales que han modelado en diferentes contextos geopolíticos las percepciones sociales del cambio político a través de la producción de conocimiento histórico y de narrativas colectivas.

Las "transiciones” para sociedades como la colombiana que han experimentado guerras prolongadas suponen, en la verdad histórica, el apoyo financiero y la recuperación psicosocial de elementos de restitución y reparación; sin embargo, estos dos autores problematizan esta noción y la relacionan con la acomodación de las políticas económicas neoliberales 
para la reconstrucción nacional (Grunebaum y Castillejo, 2007), en las que se diluyen los derechos de las víctimas en discursos políticos de transición y, en caso de refutar este tipo de dinámicas, se les califica como objetoras de la reconciliación.

En esta línea, la restitución y reparación como resultado del agenciamiento colectivo, individual e institucional son merecedoras de discusión y problematización en concordancia con el enfoque de derechos, bajo el cual se propende el reconocimiento de las personas víctimas del conflicto armado y de los daños que ellas y sus familias padecieron a consecuencia de este. Además, implica balances en torno a las acciones adelantadas en razón de: verdad histórica, apoyo financiero y recuperación psicosocial, pues con esto los procesos adquieren lecturas transversales para posterior análisis histórico.

Como mencionan Grunebaum y Castillejo, las tecnologías de gobernabilidad para la reconstrucción nacional recogen los esfuerzos sociales, políticos y económicos de los procesos de transición, y en ellos, la política pública referente a la reparación integral de quienes fueron víctimas de la guerra. En Colombia, las tecnologías de gobernabilidad dan cuenta del engranaje estatal que sustenta dicho propósito y en el que cada uno de los sectores del Estado de manera presupuestal y técnica aporta a esa mirada sistémica.

Bajo estas claridades, este documento está encaminado, en primer momento, a intentar dilucidar el concepto de reparación desde la perspectiva del trabajo de la Comisión Nacional de Reparación y Reconciliación (CNRR), la Comisión Colombiana de Juristas (CCJ), la Ley de Victimas y Restitución de Tierras - 1448 de 2011 - y el Centro de Investigación y Educación Popular, Cinep; a continuación, se sitúan algunos de los puntos de inflexión sobre este concepto al relacionarlo con la noción de agenciamiento de la memoria en la escuela, para, finalmente, ofrecer algunas consideraciones generales, que no pretenden ser conclusiones, sino aportes inacabados sobre el reto de pensar las responsabilidades 
sociales con relación a la reparación de personas que han sido víctimas de conflicto armado.

\section{La reparación: una responsabilidad social}

La categoría de reparación está asociada a los mecanismos de justicia transicional que se han llevado a cabo en el mundo contemporáneo en diferentes países con conflictos internos o externos. Naciones Unidas la define como:

Cualquier proceso en el que la víctima y el ofensor y, cuando sea adecuado, cualquier otro individuo o miembro de la comunidad afectado por un delito participan en conjunto de manera activa para la resolución de los asuntos derivados del delito, generalmente con ayuda de un facilitador (ONU, 2006, p.9).

Por su parte, la justicia transicional es comprendida como el mecanismo legal para garantizar la dignidad e igualdad de cada una de las partes, con las que se intenta promover la implementación de metodologías flexibles y variadas que puedan adaptarse a las circunstancias, la tradición legal, los principios y filosofías de los sistemas penales de cada nación. Dentro de sus premisas está reconocer a las víctimas y promover iniciativas de paz, reconciliación y democracia. Por otro lado, también ha sido asumida como un fenómeno jurídico mediante el cual se instalan regímenes de impunidad, en los que a través de meras calificaciones pueden resolverse realidades de enorme complejidad (Feierstein, 2012, p.20).

Se puede decir que la justicia transicional es un concepto que genera controversias y las múltiples aristas desde donde puede definirse representan un asunto de interés; sin embargo, de manera general es posible entenderlo como una transformación radical en el orden social y político de un país para pasar de un estado de guerra civil a un orden social político, o de una dictadura a un orden democrático (Uprimny, Saffon, Botero, y Restrepo, 2006). 
En Colombia, la justicia transicional, según la Ley de Victimas y Restitución de Tierras ${ }^{1}$, ha sido comprendida como:

Los diferentes procesos y mecanismos judiciales o extrajudiciales asociados con los intentos de la sociedad por garantizar que los responsables de las violaciones contempladas en el artículo $3^{\circ}$ de la presente Ley, rindan cuentas de sus actos, se satisfagan los derechos a la justicia, la verdad y la reparación integral a las víctimas, se lleven a cabo las reformas institucionales necesarias para la no repetición de los hechos y la desarticulación de las estructuras armadas ilegales, con el fin último de lograr la reconciliación nacional y la paz duradera y sostenible (Ministerio del Interior, 2011, p.19).

En este sentido, la propuesta transicional en Colombia está orientada por siete principios rectores que configuran, a nivel internacional, la estrategia para afrontar un periodo violento: acceso a la justicia; búsqueda de la verdad e investigación de violaciones del pasado; garantía de los derechos de las víctimas con recursos y reparaciones de parte del Estado; investigación, sanciones y medidas administrativas; conmemoración, educación y preservación de la memoria histórica; enfoque a grupos indígenas tradicionales, religiosos y otros; y reforma institucional y buen gobierno (International Human Rights Law Institute, 2002, p.5).

Bajo estos principios de la justicia transicional, la reparación se comprende desde un enfoque integral que garantiza como mínimo cinco medidas: restitución, indemnización, rehabilitación, satisfacción, y garantías de no repetición, convirtiéndose en "un proceso que busca dignificar a las víctimas mediante medidas que alivien su sufrimiento, compensen las pérdidas sociales, morales y materiales que han sufrido y restituyan sus derechos ciudadanos” (Comisión Nacional de Reparación y Reconciliación, 2007, p.19), posición que se reafirma en el artículo 25 de la Ley

1 La Ley de Víctimas y Restitución de Tierras 1448 fue promulgada en el año 2011, con el objetivo principal de reconocer y reparar a las víctimas del conflicto armado, además de proporcionar las condiciones para la construcción del marco jurídico para la paz. 
de Víctimas y Restitución de Tierras de 2011, donde que se establece el Derecho a la reparación integral:

Las víctimas tienen derecho a ser reparadas de manera adecuada, diferenciada, transformadora y efectiva por el daño que han sufrido como consecuencia de las violaciones de que trata el artículo $3^{\circ}$ de la presente Ley. La reparación comprende las medidas de restitución, indemnización, rehabilitación, satisfacción y garantías de no repetición, en sus dimensiones individual, colectiva, material, moral y simbólica. Cada una de estas medidas será implementada a favor de la víctima dependiendo de la vulneración en sus derechos y las características del hecho victimizante (Ministerio del Interior, 2011).

Así las cosas, la reparación es un derecho fundamental que tienen todas las víctimas directas de una violación, o sus familiares, quienes deben ser reparados física, material y emocionalmente. A nivel colectivo, se deben garantizar medidas que reconozcan oficialmente las violaciones e identifiquen sus causas en espacios públicos con la participación de diferentes sectores de la sociedad. Este conjunto de medidas busca

contribuir a devolver a las víctimas, en lo posible, a la situación en la que estaban antes de que ocurrieran las violaciones. Aunque regresar a la misma situación es imposible en muchos casos, la reparación apunta a extender todas las garantías para llegar a recrear esta situación que existía antes de las violaciones (Comisión Colombiana de Juristas, 2007, p.26).

Desde esta perspectiva, la reparación, al igual que la justicia y la verdad, es un derecho legítimo que ha ocupado un lugar importante en los organismos y el derecho internacional. El sacerdote jesuita Javier Giraldo, quien ha dedicado gran parte de su vida al acompañamiento a las víctimas del conflicto armado en la ardua tarea del restablecimiento de sus derechos, se ha empeñado en señalar la importancia que tiene la reparación como un campo enorme, en el que es el Estado es responsable 
de sentar las bases para proporcionar los medios legales y económicos para que pueda darse.

La reparación es una dimensión intrínseca de la justicia y trata de volver a equilibrar la balanza de la realidad, que había quedado ventajosamente inclinada en favor del victimario, reconstruyendo en lo posible, o recompensando en su peso, lo que el victimario destruyó, y asegurando que su poder destructor no vuelva a imponerse (Giraldo, 2000).

En concordancia con este fin, durante el proceso de reparación se debe permitir la participación directa de las víctimas en el diseño y ejecución de planes y programas referentes al tema, pues son ellas las idóneas para proponer mecanismos adecuados que lleven a restablecer su vida, su historia, sus comunidades y su relación con el Estado, ya que, operacionalmente, el concepto de reparación también refiere al diseño de "programas de cobertura masiva, que constituyen intentos de proveer, de manera directa, beneficios a las víctimas de cierto tipo de crímenes” (Casas y Herrera, 2008, p.202).

Atendiendo a los intereses de este trabajo y a la priorización del escenario escolar, la reparación se asumirá, enfáticamente, desde las medidas de satisfacción, en las que se enmarcan las acciones y responsabilidades del sector educativo y con las que se busca la efectividad de los derechos de las víctimas en la aplicación de sanciones, actos conmemorativos y revelación pública de la verdad.

La satisfacción abarca acciones que no tienen una naturaleza pecuniaria y tienden a compensar el detrimento de bienes no patrimoniales, entre ellos, de manera fundamental, el derecho a la justicia y el derecho a la verdad. Las medidas de satisfacción buscan, asimismo, la recuperación de la memoria de las víctimas, el reconocimiento de su dignidad, la recuperación o reafirmación de su condición de sujetos de derechos humanos y el consuelo de sus familiares, y contemplan de manera especial, las medidas 
simbólicas de reparación (Comisión Nacional de Reparación y Reconciliación, 2007, p.89).

De esta manera, la Comisión Nacional de Reparación y Reconciliación -en relación con las medidas de satisfacción - señala que la escuela debe ser coherente con el esclarecimiento de la verdad, la reconstrucción de la memoria histórica, la aplicación de la justicia y las reformas institucionales (Comisión Nacional de Reparación y Reconciliación, 2007 , p.24). Esta afirmación se ratifica con los artículos $145^{2}$ y $149^{3}$ de la Ley de Víctimas y Restitución de Tierras de 2011, en los que se invita al Ministerio de Educación Nacional y otras instituciones a atender a las víctimas por medio de la promoción de una pedagogía social para la reconciliación y el reconocimiento de la memoria histórica.

\section{El componente psicosocial en la escuela: aportes a la reparación}

En sintonía con lo anteriormente mencionado, el reconocimiento del conflicto armado en Colombia ha visibilizado discursos oficiales y subalternos respecto a las responsabilidades en los ejercicios de reparación por parte de diferentes sectores de la sociedad, en especial lo relacionado con el campo psicosocial. El sector educativo no ha sido la excepción,

2 Art. 145, Ley 1448/2011: "El Ministerio de Educación Nacional, con el fin de garantizar una educación de calidad y pertinente para toda la población, en especial para poblaciones en condición de vulnerabilidad y afectadas por la violencia, fomentará desde un enfoque de derechos, diferencial, territorial y restitutivo, el desarrollo de programas y proyectos que promuevan la restitución y el ejercicio pleno de los derechos, desarrollen competencias ciudadanas y científico-sociales en los niños, niñas y adolescentes del país; y propendan a la reconciliación y la garantía de no repetición de hechos que atenten contra su integridad o violen sus derechos”.

3 Art. 145, Ley 1448/2011: "El Ministerio de Educación Nacional, con el fin de garantizar una educación de calidad y pertinente para toda la población, en especial para poblaciones en condición de vulnerabilidad y afectadas por la violencia, fomentará desde un enfoque de derechos, diferencial, territorial y restitutivo, el desarrollo de programas y proyectos que promuevan la restitución y el ejercicio pleno de los derechos, desarrollen competencias ciudadanas y científico-sociales en los niños, niñas y adolescentes del país; y propendan a la reconciliación y la garantía de no repetición de hechos que atenten contra su integridad o violen sus derechos”. 
pues no casualmente se mantiene vivo el debate en torno a si la escuela debe dar atención o acompañamiento en el marco de la reparación, situando con privilegio misional al acompañamiento pedagógico, en el que se reconocen elementos psicosociales dentro de la trayectoria educativa del sujeto.

Los antecedentes de esto se remontan a la mirada psicologista sobre la escuela y las propuestas con enfoque sistémico del desarrollo psicocognitivo, que otorgaron un lugar protagónico a los profesionales de la orientación escolar. Se debe recordar que, en 1974 bajo la Resolución $1084^{4}$, en Colombia fue creado el servicio de orientación y asesoría escolar, asociado a la prevención primaria de las enfermedades mentales, trastornos emocionales y perturbaciones psicosomáticas.

A lo largo de los años, la normatividad que rige la orientación escolar ha buscado su transformación hacia abordajes un tanto más integrales, por ejemplo, la Ley 1098 de noviembre de $2006^{5}$ enfocó la orientación escolar a formar a niños, niñas, adolescentes y sus familias en la cultura del respeto a la dignidad, el reconocimiento de los derechos de los demás, la convivencia democrática, los valores humanos y la solución pacífica de los conflictos; en esa misma línea, el Acuerdo 518 de diciembre de $2012^{6}$ constituyó equipos interdisciplinarios de orientación escolar

4 Resolución 1084 del 26 de febrero 1974, por la cual se crean los servicios de orientación y asesoría escolar en colegios dependientes del Ministerio de Educación Nacional, considerando que "el servicio de orientación y asesoría escolar debe estar integrado al proceso educativo, ya que este incide sobre la personalidad global de los educandos y por consiguiente ha de orientarse de manera que se preserva la salud mental de estos” (Ministerio de Educación Nacional, 1974).

5 El Código de la Infancia y la Adolescencia "tiene por finalidad garantizar a los niños, a las niñas y a los adolescentes su pleno y armonioso desarrollo para que crezcan en el seno de la familia y de la comunidad, en un ambiente de felicidad, amor y comprensión. Prevalecerá el reconocimiento a la igualdad y la dignidad humana, sin discriminación alguna” (Congreso de la República, 2006).

6 Por medio del cual se constituyen equipos interdisciplinarios de orientación escolar en las instituciones educativas oficiales del Distrito Capital: "La Secretaría Distrital de Educación constituirá equipos interdisciplinarios de orientación escolar coordinados por orientadores escolares e integrados por profesionales especializados en convivencia escolar, resolución de conflictos y atención integral a la comunidad educativa, que estén vinculados a la Institución.” Artículo 1, Acuerdo 518 de diciembre de 2012 . 
en las instituciones educativas oficiales del Distrito Capital para promover la convivencia escolar, la resolución de conflictos y la atención integral a la comunidad educativa.

Estos son breves ejemplos del amplio campo normativo en el tema, que muestran el cometido de las políticas educativas en el involucramiento del escenario escolar en la mirada psicosocial. La normatividad señalada da cuenta del reconocimiento de las realidades escolares cambiantes, y en ellas, el conflicto, los derechos, la convivencia democrática y los marcos sociales del desarrollo psicosocial, ampliando así el margen de acción de los orientadores escolares y acogiendo la práctica educativa como aliada para abordar problemáticas que inciden sobre la escuela y sus entornos.

El campo psicosocial ha tenido una acogida significativa durante las últimas tres décadas: la escuela se ha acercado a parte de los discursos sistémicos ya mencionados, y de igual manera, ha delimitado poco a poco sus funciones y responsabilidades frente al tema; sin embargo, el reto continúa siendo

[entender] los procesos educativos como herramientas complementarias al trabajo de acompañamiento psicosocial, dirigido a personas y comunidades excluidas y víctimas, enmarcados en procesos colectivos de incidencia política; articulados a la exigibilidad de derechos humanos y orientados al desarrollo de las competencias ciudadanas en los diferentes sectores de la población colombiana. [...] la intervención psicosocial en contextos complejos, como es el caso colombiano, no debe restringirse a la atención y apoyo de las víctimas directas de la violencia sociopolítica y el conflicto armado, sino que debe apuntar principalmente a la concientización de los diferentes sectores de la sociedad (Girón, 2016, p.175).

El campo psicosocial está en un proceso de sinergia con el espacio escolar, en el que sea factible la configuración de "un marco para identificar, comprender y atender problemáticas y recursos individuales generados por la interacción histórica entre el sujeto y el contexto social” (Agencia 
Colombiana de Reparación, 2010, p.30), que se conciba como un componente importante en el agenciamiento escolar de la memoria social y el trámite de las versiones históricas de una sociedad en la que 8604 210 personas han sido víctimas directas del conflicto armado.

En los planteamientos del Ministerio de Educación Nacional respecto a la educación para la $\mathrm{paz}^{8}$, se consignaron en las Orientaciones generales para la implementación de la Cátedra de la Paz en los establecimientos educativos de preescolar, básica y media de Colombia, tres enfoques para asumir la paz: específico ${ }^{9}$, amplio $^{10}$ y de formación ciudadana ${ }^{11}$, en los que el manejo constructivo de emociones propias, la reparación, la participación democrática y el respeto por la pluralidad son pilares constitutivos; aparte de ello, estos enfoques fueron propuestos para abordar de manera transversal algunos de los doce ejes de la Cátedra de la Paz ${ }^{12}$ en las instituciones educativas en procura del posicionamiento de la paz como tema transversal (Ministerio de Educación Nacional, 2015).

7 Cifra reportada por la Unidad para las víctimas en el Registro Único de Víctimas —URV-. Fuente consultada en diciembre de 2017.

8 La educación para la paz se reafirma con el Decreto-Ley 1732 de 2015 para desarrollo de la Cátedra de la Paz.

9 Referido al manejo constructivo de los conflictos, el perdón, la reparación y la reconciliación.

10 Relacionado con la noción de calidad, donde el derecho a la educación es garantizado a todos los miembros de la sociedad, con el objetivo que esta se torne más equitativa.

11 Responden al respeto de las normas, bienes públicos, la construcción de memoria histórica y la reducción de inequidades.

12 La Cátedra de la Paz fue instaurada bajo la Ley 1732 del año 2014 y el Decreto 1038 de 2015, en ella se proponen doce ejes para el abordaje y construcción de la paz en las instituciones educativas (justicia y derechos humanos; uso sostenible de los recursos naturales; protección de las riquezas culturales y naturales de la nación; resolución pacífica de conflictos; prevención del acoso escolar; diversidad y pluralidad; participación política; memoria histórica; dilemas morales; proyectos de impacto social; historia de los acuerdos de paz nacionales e internacionales). 
La reparación integral, como ya se señaló, insta a ciertos tipos de medidas, de las que la satisfacción hace parte y alude a los compromisos educativos; sin embargo, los alcances de la escuela se inscriben en el acompañamiento pedagógico, al que se le apuesta con reconocimiento del enfoque psicosocial, sin pretender que se realice atención de este tipo, dado que esta última hace parte de las actividades, procedimientos e intervenciones diseñadas por el Ministerio de Salud y Protección Social en el marco del Programa de Atención Psicosocial y Salud Integral a Víctimas ${ }^{13}$ (Papsivi), es decir, no corresponde ni responde al ejercicio escolar- educacional.

Esta compleja labor, en sintonía con los ejercicios de reparación que se realicen en la escuela, requiere de la deconstrucción de los lugares tradicionales de enunciación y agenciamiento de los sujetos pedagógicos y su dimensión subjetiva, individual, relacional e interpersonal, al igual que la capacidad empática con la que es posible sentir algo compatible o similar a lo que vivió otro ser humano. En esta lógica, con el objetivo de lograr un manejo constructivo de la memoria histórica sobre el conflicto armado interno, dichas orientaciones abordan la comprensión de la historia, el desarrollo de la empatía, el pensamiento crítico y la complejidad desde perspectivas variadas:

La empatía es relevante para todos los temas identificados de educación para la paz. [...] Con respecto a la memoria histórica, la empatía permite comprender lo que pudieron sentir personas en el pasado que vivieron situaciones dolorosas como, por ejemplo, ser víctimas de violencia, y relacionarlo con lo que pueden sentir quienes están siendo víctimas de la violencia en el presente (Ministerio de Educación Nacional, 2015, p.52).

13 Papsivi es el conjunto de actividades, procedimientos e intervenciones interdisciplinarias diseñados por el Ministerio de Salud y Protección Social para la atención integral en salud y atención psicosocial. Podrán desarrollarse a nivel individual o colectivo y en todo caso ser orientadas a superar las afectaciones en salud y psicosociales relacionadas con el hecho victimizante (Decreto 4800 de 2011, artículo 164). 
Para esto es necesario trabajar desde la integralidad, al igual que desde su articulación a las dimensiones del ser humano y las formas diversas de relacionarse y significar el mundo. La integralidad en los procesos de reparación es un reto porque establece la creación y comprensión de expresiones diferentes a las académicas, a las instauradas en el currículo tradicional y a las prácticas pedagógicas de orden jerárquico docente-estudiante. La empatía tanto como la integralidad en este tipo de procesos convergen paulatinamente en la escuela, junto con los elementos que la componen en tiempo y espacio, como salas de aula, planes de estudio, proyectos educativos institucionales, propuestas pedagógicas transversales y procesos de formación docente, entre otros.

Algunas perspectivas de la psicología contemporánea ofrecen componentes fundamentales para incluir en el acompañamiento pedagógico procesos que articulan la vitalidad de cada sujeto; la Escuela de Cultura de Paz de Barcelona ha explicitado que la paz se aprende practicando con la toma de consciencia y la capacidad crítica ante realidades que signifiquen violencias, por ello, la educación para la paz y las acciones que de esta derivan pueden ser transmitidas con una mirada metodológica socio afectiva que permita entender la escuela desde dos dimensiones complementarias: como centro de convivencia y, por lo tanto, de educación en la convivencia y la paz, y como centro educativo, es decir, de educación para la paz, y la convivencia (Carieta, 2017). De esta manera, se debe entender que

para materializar el sueño de la paz es necesario fortalecer las capacidades de las personas de modo tal que puedan transformar las relaciones de poder, en la búsqueda de que todos y todas se reconozcan como sujetos empoderados capaces de pensar de manera diferente sus realidades y actuar para transformarlas (PNUD, 2015, p.11).

Así, la empatía y la integralidad del sujeto en acompañamientos pedagógicos versan en la experiencia de vida como materia prima para el reconocimiento personal y colectivo. Por lo tanto, las capacidades 
emocionales se tornan dinámicas y contextualizadas social, espacial y cronológicamente, y serán definidas por su papel activo en la sociedad al posibilitar la participación de los sujetos pedagógicos en las transformaciones del destino colectivo (Secretaría de Educación Distrital, 2014).

\section{Agenciamiento de memoria, apuesta por la reparación}

Es evidente que los cambios, dependiendo de su trascendencia, transforman las relaciones de un sistema, sus piezas, engranajes y funcionamiento; de esta manera, comparto la mirada que reconoce los cambios sistémicos propiciados por el agenciamiento que se produce en su interior. La noción de agenciamiento aquí se retoma desde los presupuestos de Gilles Deleuze, quien la asume como lectura de la realidad desde su complejidad y composición heterogénea, es decir, la comprensión de la sociedad como conjunto de los seres humanos y su relación con otros seres, objetos y formas diversas.

Esto denota que el agenciamiento está asociado a una red de dispositivos de poder, los cuales normalizan y constituyen la configuración de verdades, de manera heterogénea, porque las disposiciones no son iguales y no se mantienen intactas, se transforman al ser históricamente asignables y simbióticas. Parte de estos cambios pueden ser producto de territorialidades o reterritorializaciones que dan lugar al entendimiento e interiorización de las formas de nombrar la realidad, asumiendo una mirada diferencial tanto en las relaciones de poder como en los espacios que ocupan (Deleuze, 1995).

El agenciamiento ratifica un componente semiótico a través de la especificidad de los signos en la configuración de sistemas de personas y objetos según su pluralidad y unidad dentro de la sociedad (Deleuze, 1964, p.13); así, el agenciamiento retoma la influencia heterogénea de los enunciados, los elementos discursivos y las formas de incorporar estos a las microrrelaciones por medio de la multiplicidad de interpreta- 
ciones y dispositivos que dan sentido al ejercicio de nombrar los acontecimientos por medio de variadas manifestaciones lingüísticas.

Ahora bien, la asociación entre agenciamiento y memoria se comprende como propuesta para interpretar los ejercicios de reparación en la escuela, susceptibles a ser leídos como acciones y formas diversas de un campo con macro y micropoderes. La reparación de las personas que han sido víctimas del conflicto armado se circunscribe a la circulación de enunciados, que expuestos como objetos de análisis dejan ver un tipo de construcción de historia, y lo que es aún más interesante, su dominio discursivo sobre un grupo social y la producción de sus narrativas.

Desde esta visión, el dominio discursivo en los ejercicios de memoria en clave de procesos escolares de reparación se sustenta en la idea de que existe un enunciado, un conjunto de signos y símbolos que otorgan significado a la realidad, y el cual, ni la lengua ni el sentido pueden agotar por complemento (Foucault, 1970, p.46). El enunciado está ligado a un gesto de escritura o palabra abierto a la existencia remanente de la memoria, pues no se desvincula de otros enunciados que lo preceden, es decir, los enunciados corresponden a una experiencia histórica en la que los seres humanos los producen, reproducen y transforman dependiendo de sus intereses.

Un ejemplo claro, que logra articular lo señalado anteriormente sobre el campo psicosocial en la escuela y el agenciamiento como sistema heterogéneo, es la confluencia de representaciones en torno a la noción de víctima. El componente semiótico del enunciado de "víctima" es una consecuencia histórica,

la víctima es el resultado de un determinado procedimiento discursivo, que la categoriza y estigmatiza [...] la víctima se asume como pasiva, desprovista de agencialidad y de capacidad para rebelarse, oponerse, dirimir, resistir desde lo cultural y político, su resistencia se lee desde su capacidad de aguante para seguir sufriendo (Merchán, 2016, p.120). 
Por lo tanto, el acompañamiento psicosocial hace parte del significado de esa realidad, al igual que el reconocimiento de miradas contrapuestas sobre las víctimas, sus realidades y sus capacidades de agenciamiento.

La pluralidad del dominio discursivo sobre hechos históricos en Colombia durante los últimos veinte años instiga a evaluar las representaciones con las que se ha significado el enunciado de víctima y a desmitificar las miradas víctimizantes, a cambio del posicionamiento de interpretaciones que reconocen la capacidad de agencia y las acciones transformadoras. La pluralidad del dominio discursivo posiciona las narrativas elaboradas a una o varias voces que en la subalternidad han construido versiones históricas sobre la realidad del conflicto, y que por medio de diversas expresiones narrativas elaboran memoria social del conflicto armado.

De esta manera, los olvidos y recuerdos se asumen en las palabras y en el recorte semántico de una lengua, lo que Huyssen atribuye a las estrategias narrativas para el uso ocasional del lenguaje en la construcción de consenso sobre el pasado, que en contextos nacionales muchas veces se torna en cliché producto de un discurso memorialista, omnipresente, excesivamente público en medio de una mimesis narrativa (Huyssen, 2011).

El carácter narrativo en el tema de memoria - y ahora su relación con el agenciamiento - está basado en el sentido de las palabras y los nuevos significados que se crean a partir de los usos y abusos de los discursos, en tanto la cultura de la memoria se mantiene o transforma. La cultura de la memoria intenta describir las constelaciones de historias y memorias que emergieron en diferentes latitudes en la década de los años noventa del pasado siglo: se trata de memorias que se mantienen, alimentan, conmemoran y reproducen bajo intereses definidos en necesidades de recuperar la base temporal y espacial de la vida, en medio de los avatares del consumo y mercantilización del recuerdo (Huyssen, 2011).

Por su parte, Jelin resalta el significativo papel de la memoria como mecanismo cultural para fortalecer sentidos de pertenencia e identidades 
en determinados grupos o comunidades, y acogiéndose a los postulados de Huyssen sobre la cultura de la memoria, reconoce el auge de los movimientos memorialistas coexistentes a la valoración de lo efímero, el ritmo rápido, la fragilidad y la transitoriedad de los hechos de la vida, situación que es realmente polémica cuando se vincula la memoria a acontecimientos traumáticos de violencia política, situaciones de represión y violación de derechos humanos (Jelin, 2002).

Conforme esto, casos como Colombia requieren de agenciamientos de memoria que bajo funcionalidades culturales atiendan también los requerimientos de la búsqueda de verdad, justicia y reparación. El pasado reciente no puede convertirse en una dimensión temporal para el turismo de la memoria, en la que se va y viene, transformándolo en objeto de consumo según las conveniencias políticas del presente, es decir, promoviendo la reificación del pasado, "que se transforma en un objeto de consumo, al que se embellece, se neutraliza y se hace rentable, se prepara para ser recuperado y utilizado por la industria del turismo y el espectáculo” (Traverso, 2007, p.14); por el contrario, la memoria y los múltiples estudios nacionales alrededor de esta deben proveer elementos de entendimiento de la cronología del conflicto armado, dando sentido a las formas diversas de resistencia a la muerte, la colectivización de las versiones sobre lo acontecido y las reparaciones simbólicas a la sociedad en general.

Es claro que la memoria desde esta perspectiva no es un registro espontáneo, requiere de un sentido en el presente y futuro; es la acción de grupos sociales que reafirman identidades y afiliaciones al pasado, con diferentes agenciamientos que involucran tratamientos de los recuerdos en lo público y lo privado. El sentido de la memoria desde esta mirada es social, porque se encuentra afincada en enunciados diversos que transitan por el imaginario social con autonomía relativa y organizada según los intereses del grupo (Vezzetti, 2007).

La memoria implica referirse a elementos que están vivos o son rescatados en el imaginario. La memoria social se concibe como un "componente 
indisociable que impregna buena parte de los fenómenos y procesos sociales, y que posibilita en algún sentido la continuidad de lo social" (Vásquez, 2001, p.24). Para hablar de memoria social se debe admitir que la temporalidad no es del orden del acontecimiento, sino de la coexistencia de diversos pasados y su recuperación.

Mirar la sociedad colombiana desde la heterogeneidad significa reconocer que cada sujeto responde a un cuerpo social, que en un espacio determinado elabora y agencia su memoria a partir de la interiorización y relación con las disposiciones presentes en su contexto; implica también reconocer las representaciones que se articulan simbólicamente con su grupo, la construcción del lazo social y la formación de identidades en un territorio.

La apuesta por situar la memoria que se construye y deconstruye en la escuela en un campo agenciado no responde a un imperativo unilateral ni de definiciones univocas, pues significaría el riesgo de caer en estrategias de conservación del recuerdo con el sacrificio de la parálisis del presente; por el contrario, agenciar memoria para la reparación parte de elaboraciones de los daños que ha dejado la guerra, donde los ámbitos de creación de sentido, las representaciones y las experiencias denotan una contribución a ejercicios de reparación integral (Feierstein, 2012, p.66).

\section{Agenciamientos de memoria social en la escuela}

Acoger las nociones de reparación, memoria y agenciamiento en el escenario escolar amerita señalar que estas representan una carga simbólica que complejiza la lectura y el análisis que se realice sobre su quehacer. El aparato educativo de la escuela se recoge en medidas pedagógicas, administrativas y financieras de orden nacional e internacional propuestas para su funcionamiento, convirtiéndolo así en un innegable símbolo de los tiempos, en una metáfora de progreso y en una de las mayores construcciones de la modernidad (Pineau, 1996). Se trata de una construcción históricamente determinada, que hoy denota un 
proceso de deslegitimación social acelerado, con una diversificación de ofertas educativas que no se reducen a la escolar (Martínez, 2015).

Esta perspectiva nos coloca ante las condiciones materiales de una escuela con necesidades heterogéneas, acuñadas a la conveniencia de pensar la reparación teniendo presente la diferencia, la diversidad y la equidad con justicia social; por eso, se reivindica en sí mismo el argumento reflexivo de la responsabilidad de asumir tareas de reparación con múltiples puntos de vista sobre el pasado individual y colectivo.

Como se mencionó antes, en el marco de la justicia transicional colombiana existen requerimientos jurídicos asignados al sector educativo. La educación debe aportar a la construcción de sentido sobre la existencia de cada uno de nosotros en una tradición y una comunidad determinada; de igual manera, está encargada de propender a una cultura de paz desde los efectos subjetivantes de reconocimiento propio y alterno. En la Ley de Víctimas y Restitución de Tierras de 2011 es clara la necesidad de trabajar con enfoques de derechos, diferenciales, territoriales y restitutivos, para que niños, niñas, adolescentes, jóvenes y adultos tiendan a la reconciliación y la garantía de no repetición de hechos que atenten contra su integridad. (Ministerio del Interior, 2011)

La necesidad de mirar detenidamente el tipo de responsabilidades que le aquejan a la escuela dentro del amplio campo educativo y las herramientas con las que cuenta para responder a las especificidades de las medidas de satisfacción, en especial a la construcción de una pedagogía social para la reconciliación y el reconocimiento de la memoria histórica, son en sí mismas un ejercicio de análisis sobre la constitución histórica de la escuela y la forma en cómo se ha acercado a estos temas.

$\mathrm{Al}$ respecto, Carretero (2007) afirma que la memoria en la escuela no es un tema nuevo, por el contrario, está arraigado a procesos que sustentan identidades, historias nacionales y representaciones colectivas del pasado común. Para efectos de acciones reparadoras, el análisis y la reflexión deben situarse en intentar entender qué tipo ejercicios de 
memoria se promueven sobre la historia reciente de una sociedad que enfrentó el conflicto armado por un largo período de tiempo ${ }^{14}$.

Con miras a implementar agenciamientos de memoria que contribuyan a la reparación integral, es fundamental reconocer que la historia escolar tiene un papel protagónico en la asimilación histórica, en la incursión al cuerpo disciplinar de la historia, sus procedimientos específicos para la construcción del conocimiento histórico y el acercamiento o distanciamiento de versiones históricas. El agenciamiento de la memoria requiere de posiciones activas en la elaboración de memorias e historias, en las que los relatos singulares y plurales hablen de lo que ha pasado, de las afectaciones y de quiénes lo hicieron posible, de tal manera que este se torne pluridireccional en medio de un mosaico de diversas fuentes, sujetos y narrativas históricas.

No se trata de sustituir las formas en las que la escuela ha agenciado la memoria social por otras distintas, sino de captar que cuando hablamos de agenciamiento nos referimos a muchas posibilidades de ser y hacer, y desde donde es factible replantear enunciados que por valoración histórica no son significativos en los ejercicios de reparación. La pregunta acerca de cómo se viene haciendo, cómo se concibe la reparación y de qué otras maneras es factible hacerlo crea una tentativa de transformación.

14 La historiografía colombiana con respecto al estudio del conflicto armado ha proporcionado diversas periodizaciones que dan cuenta de los recortes temporales y características de estos; sin embargo, los variados estudios subrayan la dificultad de establecer una fecha exacta de iniciación del conflicto. Por ejemplo, el Grupo de Memoria Histórica, en el informe ¡Basta ya! Colombia: memorias de guerra y dignidad (2014), aclara la dimensión y la complejidad que implica el esclarecimiento histórico y la comprensión de la guerra. Dicho informe da cuenta de más de cincuenta años de conflicto armado en nuestro país, explicándolo por medio de cuatro periodos históricos: 1958-1982, 1982-1996, 1996-2005 y 2005-2012. El historiador Marco Palacio señala que 1930-1932 ó 1948-1950 marcan un conflicto orientado políticamente y 1950-1953 y 1956-1958 corresponden a pérdida de la filosofía superior de la acción a cambio de la agresión; en 1962 se da la lucha armada. Este debate se hace evidente, nuevamente, en los doce ensayos de contribución al entendimiento del conflicto armado en Colombia elaborados por la Comisión Histórica del Conflicto y sus Víctimas (2015). 
Sin duda, a pesar del desgaste y desaprobación que la escuela ha acarreado ante el privilegio hegemónico y conservador de muchas de sus consignas misionales, sigue siendo un lugar en el que se articulan como mínimo tres aspectos que consideramos importantes para este reto transformador de la agencia: las iniciativas de pedagogías de la memoria y tratamientos públicos del pasado, la construcción de lugares diferentes a los otorgados históricamente a los sujetos y el movimiento dialéctico entre olvido y recuerdo para un equilibrio empático.

En primer lugar, las pedagogías de la memoria concebidas como procesos de dotación de sentido hacen evidente el papel activo de los sujetos dentro de su proceso identitario en la transmisión y apropiación de las memorias. Las pedagogías de la memoria a partir de la narrativa se conciben como un evento intersubjetivo, porque adquieren elementos de la historia y de la subjetividad que contribuyen a la vinculación de la vida y la sociedad por medio de la dotación de sentido (Ortega et al., 2015, p.136).

Las pedagogías de la memoria, ideadas como pedagogías sociales que pueden atender desde el enfoque diferencial los trabajos de la memoria, se convierten en una posibilidad de reparación, en la medida que "no conducen de forma obligada al recuerdo, sino que proveen elementos al ser humano para acercarse a eventos que le han sido nocivos, emergen como parte de un proyecto de dignificación y restitución de derechos" (Torres, 2016, p.276).

En segundo lugar, agenciar memoria sitúa a los sujetos pedagógicos en lugares diferentes a los otorgados en la estructura escolar. La carga simbólica aparece como pretexto para el emprendimiento de procesos creativos, empáticos y de resistencia. En esta perspectiva, el agenciamiento de memoria representa una plataforma de activación social, cultural y educativa, no homogénea, con posibilidades dinámicas en el contexto y por parte de los agentes que la construyen. Así, la reparación a través de agenciamiento de memorias sociales se vuelve un ejercicio dialéctico, 
con fuerzas y tensiones en las que se deslocaliza el lugar común, se resignifican y desnaturalizan las versiones sobre el accionar humano y se comprende que sociedades como la colombiana requieren de reparaciones a diferentes niveles, con responsabilidades y trascendencias que encajen en cuadros explicativos del fenómeno de la violencia, no como un decreto histórico para la conmemoración, educación y preservación de la memoria histórica, sino de miradas diferenciales prestas a ser retroalimentadas, debatidas y consensuadas con diversos grupos poblacionales.

En tercer lugar, organizaciones de víctimas del conflicto han adelantado acciones de equilibrios empáticos en pro de la reparación integral y han detectado la importancia de identificar los impactos producidos por la guerra como un esfuerzo por reducir la impunidad o la ausencia del reconocimiento del daño. Desde esta perspectiva, es fundamental comprender integralmente las dimensiones y alcances de los daños, pues la forma en la que cada sujeto individual o colectivo reacciona ante los hechos violentos es distinta dependiendo del contexto cultural, político, social o ambiental.

Al tratarse del agenciamiento de procesos de reparación en la escuela a través de pedagogías de la memoria, son niños, niñas y jóvenes quienes participan de estas propuestas de agenciamiento. Bajo esta idea, los cuadros explicativos del fenómeno de la violencia deben comprender la mirada diferencial de las acciones de memoria histórica con niños, niñas y adolescentes, en cuanto estos

tienen derecho a la verdad, en razón de lo cual la sociedad debe hacerlos participes de procesos de construcción de verdad. Para ello, es preciso su reconocimiento como sujetos de derechos y como agentes con capacidades para aportar sus experiencias y significaciones acerca de lo acaecido con ocasión del conflicto armado en procura de comprender y reparar las afectaciones diferenciadas por hechos victimizantes (Centro Nacional de Memoria Histórica, 2014, p.43). 
Esta noción implica dar un lugar a otras voces, diferentes a las de los adultos. Sin lugar a dudas, la explicación "objetiva", "veraz" y "coherente" que ha sido asignada a las narrativas adultocéntricas, como sinónimos de mayoría de edad para construir versiones que valen la pena ser integradas en relatos más amplios, deben dialogar con las narrativas de niños, niñas y adolescente y sus experiencias. ¿Qué quiero narrar? ¿Cómo quiero que me recuerden? ¿Cómo me imagino el territorio de donde son oriundos mis padres? ¿Por qué recordar a los que me hicieron daño, pero también a quienes me han hecho bien? Estas cuestiones manifiestan en lo público formas de elaborar marcos sociales significativos en la escuela.

El conocimiento del sentido común y el consentimiento de los propios sujetos de su ejercicio narrativo no pretende decaer en la saturación testimonial o en memorias literales (Todorov, 2008) en las que se vuelve insuperable el acontecimiento. La consideración de la memoria social como propuesta reflexiva debe estar acompañada de fundamentaciones históricas que puedan ser complementadas por la enseñanza de la historia, donde se reconozca a los niños, niñas y adolescentes como agentes históricos enfrentados a situaciones empáticas de transformación y coyunturas existenciales que pueden marcar sus vidas.

La preocupación por situar la importancia de las memorias sociales de los niños, niñas y adolescentes en el ámbito educativo y pedagógico recae en el carácter social que coloca al ser humano en un mundo con sentido independientemente de su edad, lo ubica simbólicamente en su experiencia histórica; por lo tanto, una pedagogía de la memoria enunciada desde la escuela no es aquella que obliga a recordar, sino que sostiene que el ser humano no puede renunciar al recuerdo, como no puede prescindir del olvido (Mélich, 2006). Es un esfuerzo por entender que la memoria no viene sola, está íntimamente relacionada con la historia y con un orden cultural que genera las posibilidades de adentrarnos en la experiencia histórica con pasado, presente o futuro. 
De esta forma, la escuela es el mejor ejemplo para vincular de manera significativa las variadas versiones, sin recusar el conglomerado de enunciados y dispositivos de poder, donde los agenciamientos de memorización o conmemoración poco reflexivos dificultan la creación de lenguajes diversos para representar lo irrepresentable, para trabajar de manera integral tanto los daños derivados del conflicto como la historia reciente de Colombia en clave de una educación para la paz. Es por esto que deslocalizar, mover del lugar común o sacudir los lugares de confort desde donde se producen las versiones históricas conlleva a reflexiones estructurales sobre nuestra historia como país, sus cambios y permanencias.

Finalmente, vale la pena decir que los procesos pedagógicos que propendan la reparación de personas que han sido víctimas del conflicto armado deben incluir ejercicios de memoria, acciones psicosociales que activen canales comunicativos diferentes a los establecidos comúnmente en la escuela y que privilegien la formación de una opinión política sobre la historia reciente de Colombia, entendiendo que

la formación política en la enseñanza de las ciencias sociales es el conjunto de acciones pedagógicas conducentes a la construcción y resignificación de las posiciones que se asumen frente a problemáticas sociales contemporáneas y su incorporación en la experiencia individual de procesos de construcción de memoria de las acciones sociales colectivas de resistencia (Sánchez y Rodríguez, 2009, p.223).

Por lo tanto, el agenciamiento de memoria social para la reparación en el ámbito escolar conlleva, en primer lugar, al extrañamiento de la existencia del otro y de sí mismo desde una mirada empática; en segundo, a las confrontaciones respetuosas entre el universo experiencial de los diferentes sujetos que conforman la escuela; y en tercero, a identificar los diversos mecanismos a los que acuden los agentes escolares para realizar procesos de memoria social. Así, la reparación empieza 
por reconocer a los sujetos, sus experiencias y las capacidades para relacionarse con el pasado y el presente.

Lo que sobresale en esta apuesta es la posibilidad de transformar las experiencias traumáticas por experiencias temporales presentes, adscritas al sujeto en espacios de reconocimiento y conciliación subjetiva e intersubjetiva, que desde la escuela pueden ser concebidas como escenarios de reparación en un país donde los daños responden a situaciones adversas con grados disímiles de responsabilidad sobre violencia y atrocidad.

\section{Consideraciones finales}

Como se mencionó al inicio de este texto, el principal interés con la escritura de estas líneas recaía en situar algunas reflexiones acerca de la relación entre agenciamiento, escuela, memoria y reparación en el contexto nacional de justicia transicional. No se pretendía colocar versiones acabadas sobre el tema, o perspectivas unidireccionales, por el contrario, se esperaba socializar elementos para la lectura de la difícil tarea de hablar de reparación en el escenario escolar, encontrando como mínimo tres grandes puntos de inflexión respecto esta relación.

Primero, la escuela, conforme la normatividad establecida en el Decreto-Ley 1732 de 2015 para desarrollo de la Cátedra de la Paz y las propuestas de desarrollo de competencias y capacidades ciudadanas, es responsable de trabajar en educación para la paz; además de ello, la Ley de Víctimas y Restitución de Tierras 1448 de 2011 explicita la idea de promover una pedagogía social de la memoria que contribuya a la reparación y la reconciliación.

Este punto es altamente controversial, porque si bien la escuela es un escenario clave para la construcción de paz y memoria, no es el único, $y$, por lo tanto, en el marco de medidas de satisfacción es necesario delimitar las acciones y estrategias que aportan a la reparación integral. 
No es responsabilidad de la escuela realizar procesos de atención psicosocial, pero sí de agenciar acompañamientos pedagógicos desde el enfoque diferencial, que promuevan los ejercicios de memoria y la construcción de historias diversas sobre lo que sucedió en pro de la reparación y la reconciliación.

En la misma vía, el agenciamiento de memoria social entrelaza múltiples discursos que convergen en relatos, versiones y formas de tramitar el pasado, lo que significa que los procesos de memoria en la escuela están supeditados a relaciones de poder generadas en la visibilización y reconocimiento de los sujetos, sus experiencias y maneras de narrarlas. Aquí, se apostó por entenderlo como ejercicios de agenciamiento,, es decir, como construcciones históricamente asignables y simbióticas, que se producen o reproducen en códigos semánticos que a su vez responden a una territorialización o reterritorialización. Sin embargo, es claro que existen un sinnúmero de maneras en las Ciencias Sociales de entender y desarrollar el tema.

Segundo, la reparación es una noción jurídica que en los procesos transicionales cobra relevancia y se torna indispensable para pasar la página de los periodos de horror. En este sentido, es necesario que las comunidades educativas cuenten con el espacio para entender lo que significa reparar, y de manera contextualizada puedan pensar posibles caminos para aportar a la reparación del tejido social y así evitar lo que Huyssen ha denominado cliché de la memoria social, donde terminan prevaleciendo los olvidos públicos del pasado y el favorecimiento de discursos memorialistas omnipresentes sobre las reparaciones integrales de las personas que fueron víctimas directas e indirectas.

Tercero, la reparación en la escuela es un proceso que requiere de ejercicios transversales y de compromisos institucionales con la práctica pedagógica, así como de acciones psicosociales sin daño y de la construcción de ambientes de aprendizajes diversos e interculturales, que colaboren al empoderamiento de los sujetos desde sus diferentes 
lugares de enunciación. Con ello, se sobreentiende que la escuela, en su contexto heterogéneo, está en la capacidad de descubrir abanicos de posibilidades en el tema de reparación y la suma de detalles de cada escuela la hace un lugar con características únicas para pensar desde sus intereses y necesidades este tema.

Por todo lo anterior, la educación es clave para entender y llevar a cabo ejercicios de reparación. De manera específica, y atendiendo a lo que está consignado en la norma, se deben privilegiar los principios de la justicia transicional de conmemoración y preservación de la memoria histórica, por lo que se requiere hacer la lectura de la escuela como lugar de agenciamiento, en la medida que incorpora intereses, formas de hacer, contar y recordar diversas. La propuesta del análisis semiótico a partir del agenciamiento y el acercamiento crítico a las formas enunciativas hace parte de procedimientos donde las condiciones del presente permiten la construcción de cuestionamientos con sentido histórico que sitúa a los sujetos en un espacio-tiempo con agencia de transformación.

\section{Referencias}

Agencia Colombiana para la Reparación (2010). Modelo de atención psicosocial para la paz. Bogotá: Alta Consejería para la Paz.

Augé, Marc (1998). Las formas de olvido. Barcelona: Gedisa.

Blair, Elsa (2005). Memorias de violencia, espacio, tiempo y narración. Controversia, (185), 1-17.

Carretero, Mario (2007). Documentos de identidad: la construcción de la memoria histórica en un mundo global. Buenos Aires: Paidós.

Casas, Andrés y Herrera, Germán (2008). El juego político de las reparaciones: un marco analítico de las reparaciones en procesos de justicia transicional. Papel político, 13(1), 197-226.

Carieta, Marina (2017). Reflexiones sobre el devenir de la Cátedra de la Paz en el Caquetá (Colombia). Recuperado en noviembre 2017 de http://escolapau. uab.cat/img/programas/educacion/ColombiaCaqueta.pdf 
Centro Nacional de Memoria Histórica (2014). Memoria histórica en el ámbito territorial: orientaciones para autoridades territoriales. Bogotá: CNMH.

Comisión Colombiana de Juristas (2007). Verdad justicia y reparación. Algunas preguntas y respuestas. Bogotá: Autor.

Comisión Nacional de Reparación y Reconciliación (2007). Recomendación de criterios de reparación y de proporcionalidad restaurativa. Artículo 52, Ley 975 de 2005, Artículo 16, Decreto 3391 de 2006. Cuadernos 1. Bogotá: Autor.

Comisión Nacional de Reparación y Reconciliación (2007). Definiciones estratégicas de la Comisión Nacional de Reparación y Reconciliación. Bogotá: Autor.

Deleuze, Gilles (1995). Deseo y poder. Barcelona: Archipiélagos.

Deleuze, Gilles (1964). Proust y los signos. Barcelona: Anagrama.

Feierstein, Daniel (2012). Memorias y representaciones sobre la elaboración del genocidio. Buenos Aires: Fondo de Cultura Económica.

Foucault, Michel (1970). Arqueología del saber. México D. F.: Siglo XXI.

Giraldo, Javier (2000). Introducción. Colombia nunca más. Recuperado en diciembre 2017 de https://www.javiergiraldo.org/IMG/pdf/Verdad_ Justicia_y_Reparacion.pdf

Girón, Claudia (2016). La dimensión psicosocial de la educación para la paz. En P. Ortega (Ed.). Bitácora para la Cátedra de la Paz. (pp. 159-185) Bogotá: Universidad Pedagógica Nacional.

Grunebaum, Heidi y Castillejo, Alejandro (2007). Presentación. Violencia, reparación y tecnologías del recuerdo: perspectivas desde África y América Latina. Antípoda. Revista de Antropología y Arqueología, (4), 5-7.

Grupo de Memoria Histórica (2014). Informe ¡Basta ya! Colombia: memorias de guerra y dignidad. Bogotá, Colombia: Imprenta Nacional.

Huyssen, Andreas (2011). Modernismo después de la posmodernidad. Barcelona: Gedisa.

International Human Rights Law Institute (2007). Principios de Chicago sobre la Justicia Transicional.

Jelin, Elizabeth (2002). Los trabajos de la memoria. Madrid: Siglo XXI. 
Martínez, Alberto (23 de noviembre de 2015). La educación en América Latina: de políticas expansivas a estrategias competitivas. Recuperado de http:// www.pedagogica.edu.co/storage/rce/articulos/44_05ens.pdf

Mélich, Joan-Carles (2006). El trabajo de la memoria o el testimonio como categoría didáctica. Enseñanza de las Ciencias Sociales, (5), 115-124.

Merchán, Jeritza (2016) La pedagogía en la Ley de Víctimas y en los post acuerdos de paz. En: P. Ortega (Ed.). Bitácora para la Cátedra de la Paz. (pp. 115-134) Bogotá: Universidad Pedagógica Nacional.

Ministerio de Educación Nacional (2015). Orientaciones generales para la implementación de la Cátedra de la Paz en los establecimientos educativos de preescolar, básica y media de Colombia. Bogotá: Ministerio de Educación Nacional

Ministerio de Justicia (2011). Decreto 4800 de 2011. Ministerio de Justicia y del Derecho, Bogotá.

Ministerio del Interior (2011). Ley de Victimas y Restitución de tierras. Bogotá: Ministerio de Justicia y del Derecho.

Ministerio de Salud (2017). Programa de Atención Psicosocial y Salud Integral a Víctimas del Conflicto Armado (Papsivi). Documento marco. Bogotá: Ministerio de Salud.

Pineau, Pablo (1996). ¿Por qué triunfó la escuela?, o la modernidad dijo: "esto es educación” y la escuela respondió: "yo me ocupo”. En H. Cocuzza (Comp.). Historia de la educación en debate (pp. 306-331). Buenos Aires: Miño y Dávila.

Programa de las Naciones Unidas para el Desarrollo (2015). Retos e iniciativas de la educación para la paz y de los derechos humanos. Bogotá: Rededupaz.

Rufer, Mario (2009). Memoria pública y usos del pasado en contextos poscoloniales. México D. F.: Colegio de México.

Sánchez, Olga y Rodríguez, Sandra (2009). Narrativa, memoria y enseñanza del conflicto armado colombiano: propuesta para superar las políticas de olvido e impunidad. En D. Gómez y A. Serna (Comps.). El papel de la memoria en los laberintos de la justicia, la verdad y la reparación (pp. 203230). Bogotá: IPAZUD. 
Secretaría de Educación Distrital (2014). Planes Integrales en Educación para la Ciudadanía y la Convivencia, Bogotá: SED

Organización de Naciones Unidas (2006). Manual sobre programas de justicia restaurativa. Nueva York: Publicaciones Naciones Unidas.

Ortega, Piedad; Castro, Claribel; Merchán, Jeritza y Vélez, Gerardo (2015). Pedagogía de la memoria para un país amnésico. Bogotá: Universidad Pedagógica.

Traverso, Enzo (2007). El pasado, instrucciones de uso. Historia, memoria politica. Madrid: Marcial Pons.

Todorov, Tzvetan (2008). Los abusos de la memoria. Barcelona: Paidós.

Torres, Ingrid (2016). Pedagogías de la memoria y la enseñanza de la historia para la construcción de conciencia histórica. En: P. Ortega (Ed.). Bitácora para la Cátedra de la Paz. (pp.263-282) Bogotá: Universidad Pedagógica Nacional.

Uprimny, Rodrigo; Saffon, María Paula; Botero, Catalina y Restrepo, Esteban (2006). ¿Justicia transicional sin transición? Verdad, justicia y reparación para Colombia. Bogotá: Centro de Estudios de Derecho, Justicia y Sociedad, Antropos.

Vásquez, Félix (2001). La memoria como acción social. Relaciones, significados e imaginarios. Barcelona: Paidós.

Vezzetti, Hugo (2007). Conflictos de la memoria en Argentina: un estudio histórico de la memoria social. En A. Pérotin-Dumon (Dir.). Historizar el pasado vivo en América (pp. 1-44). Buenos Aires: Universidad Alberto Hurtado. 